\title{
Review About Gender Discrimination Within Working Place
}

\author{
Aaron Peng ${ }^{1, *}$, Iris $\mathrm{Yu}^{2}$, Judy Wang ${ }^{3}$, Cecilia Zhang ${ }^{4}$ \\ ${ }^{1}$ Changsha Changjun High School Internatinal Department \\ ${ }^{2}$ ShenZhen Senior High School \\ ${ }^{3}$ Shanghai Guanghua International School \\ ${ }^{4}$ Shanghai Guanghua International School \\ *Corresponding author. Email: guanghua.ren@gecacademy.cn \\ Those authors contributed equally.
}

\begin{abstract}
Gender discrimination which refers to the bias based on people's gender, exist in most patriarchal societies and have been presented in many forms during people's life in different stages. With the deeply reviewing of relative sources, the presenting of gender discrimination within workplace has been proofed as a serious problem globally since some regions considered the problem as 'solved' or 'common' phenomenon instead of a serious social problem. Corporate culture has struggled people by presenting gender discrimination, especially for women during the work time. Female workers are suffering under the pressure of discriminatory corporate culture within workplace from various aspects like the sexual harassment, hidden rules for promotion, the existence of glass-ceiling and special stipulations particularly set for females like dressing code. Although both male and female workers can be limited by the discriminated corporate culture, females are the main victims who directly suffer from both written and invisible rules. The paper deeply talking about how the discrimination exist in workplace and how it affects workers especially female workers.
\end{abstract}

Keywords: Workplace, discrimination, Stereotype, Females

\section{INTRODUCTION}

Discrimination means the unfair treatment people received based on their personal characteristics like ethnicity, gender or religion [1]. When the population are staying in the minority, they are more easily considered as different with the dominant culture and face the difficulties of discrimination. Females who share the same gender identity are considered minority group in the workplace for the historical reasons like the patriarchal norms. "Historically, the principle of patriarchy has been central to the social, legal, political and economic organization of many ancient civilizations" [2]. Therefore, the terms of gender discrimination appeared in the fields used to be dominated by males like the workplace. Gender discrimination refers to a common civil rights violation that involves the disadvantageous treatment of an individuals or a group of individuals based on their gender identity [3]. The common discrimination appeared in workplace including not being hired or paying lower because of gender identity or sex orientation and being held to different standards and evaluate more harshly since the employees do not acting in the way that conforms to traditional ideas of femininity or masculinity. The gender discrimination can be considered illegal in the 'terms and conditions'. the Equal Right Advocates noted that "Terms and conditions" include but are not limited to things like job responsibilities, work hours, dress code, vacation and sick days, starting salary, and performance evaluation standards. There is also specific policy against discrimination in workplace like the prohibition of dismissal of pregnant workers. However, not only intentional movement can be discrimination, according to the Equal Right Advocates, "It could still count as discrimination if your employer does something that ends up excluding or harming workers of a particular gender identity without intending to [3]."

Gender discrimination within workplace has been noticed since the adoption of Beijing Declaration but 
after 25 years, the progress remains elusive [4]. SME loans has conducted a survey and found that over 8.2 million employees in UK feel they have been discriminated against on the grounds of their gender in 2020 [5]. The 2020 report by the Economic and Social Affairs department in UN noted that "women held only $28 \%$ of managerial positions globally in 2019 - almost the same proportion as in 1995 . And only $18 \%$ of enterprises surveyed had a female Chief Executive Officer in 2020 [6]. Those data strongly suggest that although females have the right to work and gain a job at present, they are still the minority group in the whole environment of workplace. Moreover, although there has been an Equal Pay Act in force in the UK since 1975, women still earn an average of $19.8 \%$ less than men, according to the Office of National Statistics [6]. Though more anti-discrimination acts like the equal treatment laws have created to protect gender minority and reduce the gender discrimination, both the pay gap and glass ceiling still exist remarkably [7]. The problem of gender discrimination within workplace is no longer solved and broadly affect people all over the world in both the aspects of seeking opportunities, working conditions, the image of enterprise and the terms and conditions of employees.

This paper will examine the current presentation for binary gender discrimination within workplace only. This paper is investigating the presentations of gender discrimination especially suffered by females in different aspects of workplace. Subsequently, four specific aspects will be discussed with our reviewing on relative literature sources. First is the existence of glass ceiling for women to get equal opportunities like employment, promotion and job distribution. The paper tries to connect the previous founding with the current affairs and try to gain the reason to explain the existence of glass ceiling. Also, the increase in female leaders contribute to another effect on the presentation of gender discrimination. Secondly, the literature taking about sexual harassment within workplace are considered the main presentation of discrimination. The literature for enterprise image indicates how much the patriarchal norms affect the culture of workplace and encouraging the discriminatory activities. Thirdly, the image of an enterprise is the first impression for job applicants, therefore, the effect from enterprise image can related with their level of discriminatory tendency during work time and the working environment. Our last focuses are the terms and conditions which can also imply as stipulation. There are many literatures mentioned that the policies or laws aim on reducing gender inequality within workplace have been set yet but the effect is still doubt since more unwritten stipulations are hidden under the environment.

\section{PRESENTATIONS OF GENDER DISCRIMINATION}

\subsection{Gender Discrimination: Sexual Harassment}

Cases of sexual harassment that violate individuals' dignity are numerous in workplaces. The evidence collected from Equality and Human Right Commission show that "nearly three-quarters of people who had been harassed before among all the 750 respondents, and nearly all the people who have been harassed sexually were women, while most men participants said that they hadn't been harassed [8]." Female employees are threatened with their careers from sexual harassment by superiors so that these females did not dare to ask for help and speak out about their experiences.

Not only that, it is difficult for female employees to continue to be promoted after reaching a certain position, especially in some foreign companies. According to the data, globally, women hold just $24 \%$ of senior leadership positions. It can be easily seen from the actual situation that, when it comes to the highest positions, the figure for women participants sharply reduced compared to the figure at the middle level. The data suggest that men are more likely overall to be chosen or rated as leaders, in part because they have more assertive personalities and thus speak up more. However, the judgements given to females, like weak, indecisive and hesitating, are exactly stereotypes under social reinforcement. This rigid division also leads to social misunderstanding of women's wisdom and power, which impedes females' promotion, while actually many companies that have women leaders perform better, due to that woman sometimes have traits that both men owned and don't own.

Gender inequality occurs as a prevalence in the workplace in the majority form of hidden rules and workplace bullying and is dramatically still not going to decline but instead increase even in this era of education getting advanced leading to gender issue being noticed. The hidden rules refer to those inappropriate rules left by those people occupying a dominant position, nonetheless, according to the data, the obtained significant information shows that the majority of people occupying leadership are still males and, in 2017, the employment rate of women aged 20-64 (66.5\%) was 11.5 percentage points lower than that of men aged 20-64 (78.0\%) in the European Union $[9,10]$. Which means females are forced tending to be weaker group given option to perform those hidden rules including being forced to drink with the senior, obeying sexual harassment, or even having sex with the senior worker to please the senior staff to obtain a promotion or avoid suffering from those underhand punishments from their boss [11]. This would cause a more serious females' self-materialization, for females can get an easy promotion by paying less effort, forming a vicious circle 
making these "hidden rules" more common. That is, because people in general, commonly misinterpret displays of confidence as a sign of competence, we are fooled into believing that men are better leaders than women [12]. Thus, in this case, continuously, a phenomenon would be contributed that some of man senior workers would consider those rules valued opportunities for female employees and would even consider forcing those rules on a female employee as gifting her a valued opportunity of promotion, without noticing that this could be an offensive behavior, which makes workplace bullying more likely. Besides, the commonization of the hidden rules may also make a kind stereotype towards those female employees or even all females instead of workplace.

\subsection{Gender Discrimination: image of enterprise}

The image of enterprise means the impression and judgment to an enterprise from the public. The image could be formed by the public relation action. The specific image could be established by four parts. The image of product, employees, leaders of the company, self-expecting, the public relation image and the real image from others. The image of the product and employees effect the women more and also are easier to be affected by women's right.

Product itself reflects the problem of the inequality for women. Because of the difference in appreciation of beauty, and Ro centrism and physiological structures, most of the products in the markets are not suitable for women. The physiological structure is also a large factor that women cannot enjoy the same experience of using the same product, especially using the daily supplies. As a result, the quality of life for women is not as good as that for men for a very long period. For example, male and female have a different structure of auditory systems; therefore, women cannot be as comfortable as men when using traditional earphones. However, under this situation, the first female earphone was still not invented until 2017, which means that females had undergone unsuitable earphones for plenty of years. This could show that women consumers were probably treated unfairly over the past few decades when consuming daily supplies [13].

In addition, the advertisement is an important factor for companies. There are important factors for the corporate culture, women's image might be stereotyped, in addition, the image of enterprise could be affected if the ads offense women. Unlike the propaganda, advertisement emphasizes the stereotype by showing women's image in daily lives, therefore, the image of beauty and housewife is remembered by the public. People try to use advertisement to prettifies women to please men, the image of women in advertisements are always perfect, which is not accord with women's statures in reality. For example, the advertisement of shampoo uses a female model's hair to reflect the body outline of shampoo.

The attitude of employees would also affect a companies' image, in addition, the way treating consumers is also an important factor for a company to build their image in a market. If the enterprises cannot treat women equally as male consumers, the image will be affected. In Chile, $88 \%$ of the female consumers feel discriminated when consuming. Female consumers are not satisfied and feel offense during consuming; the consumption of the product in the company will decrease. In addition, $33 \%$ of women feel harder when they ask for loan, because women are recognized that they have lower ability to pay back the loans. The discrimination actions will decrease the number of women consumers, as a result, the total number of consumers probably decrease, which is not an advantage for the company itself.

\subsection{Gender Discrimination: Stipulations}

Females are also suffering from discriminatory stipulations in the workplace. Females may be fired or reduced the wage just because they are pregnant or have the plan of pregnant in some patriarchal countries. According to the latest report of Women, Business and the Law, in 38 of the 190 economies, the legislation does not ban the firing of pregnant workers. The lack of legal aid for pregnant female workers can add to the female unemployment rate. In Canada, the employment rate for girls aged above 15 in 1960 was $29.71 \%$ and the fertility rate, the rate between the number of females during childbearing age which is usually between 16 and 46, with the number of newborn children in that year, was 3.8. But in 2020, the employment rate rose to $59.52 \%$ with decreasing fertility rate of $1.5[14,15]$. This data helps show how pregnancy can affect female employment. For many female workers, pregnancy not only forces them to be unemployed but also makes them suffer from serious mental pressure and physical challenges based on the unequal treatments like denial of promotions, redundancy, and job assignment decrease among others. The unequal treatment toward pregnant workers can give them a sense of alienation and marginalization. The special stipulation also shows in the recruitment by asking questions not related to the job content and applicant's ability. This problem can be found in most patriarchal societies like China. Females will face the question about 'how can you balance the family life with your work' which is highly discriminated since the same question will never ask a man. Things did not go that well with the announcement of protected law. Although there are anti-discrimination requirements in many societies, this invisible stipulation still exists since the employers try to find out the loopholes in the law. For example, to reduce the cost for female workers during pregnancy, the employer may 
change the working position before they are pregnant or cancel the promotion if the worker has a plan of pregnancy.

Dressing code also acts as unwritten systematical discrimination for female employees. In some industries especially service, female workers will be asked to wear certain clothes that are usually sex-based and different from male workers. The unwritten rules for office ladies to wear high heel shoes and skirt instead of pants act as visible discrimination in the workplace. According to Rahman et al., compelling women to dress in a sexually explicit manner at work, such as requiring them to wear a high heel, short skirt, tight apparel, or pants, will leave a negative impression on women [16]. Those conditions are rather prevalent. Nicola Thorp, a female employee who has been sent home for not wearing high-heel to work has launched a petition after the things happened and received more than 11000 signatures for calling the company not to force women wearing high-heel to work. This large number of signatures is direct evidence to show that how troublesome the dress-code for female in workplace is. All of those stipulations are formed under the patriarchal ideology that people consider less for the female but require more from them by ignoring the basic need during pregnancy and set a special dress code to satisfied males.

\section{CONCLUSION}

After reading and analyzing the information of four aspects of corporation culture, the paper compares the changes with time and finds some new ideas on the topic. Firstly, the origin of the discrimination seems to change since the employment rate of female workers keeps rising globally. Instead of the situation before 1972 that females were not allowed to be educated and work independently, the public, especially male entrepreneurs are more familiar with the working ability of females in the workplace. Instead of the idea suggested as that the discrimination is created under ignorance for female's ability in the workplace, it is more like a knowing bias that exists under the patriarchal ideology. Moreover, the paper discovered that the attitude of females themselves is different. There do have part of people own a supportive view with the discriminatory culture like the hidden rules since they consider it as an easier way to gain power from males. This ideology may be formed under the socialization of patriarchal culture that males will be the power holders and the only way to share the power is to satisfy them. This idea can be socialized by both the education system, media source, or the family background which require deeper researching and analysis to gain an answer.

\section{REFERENCES}

[1] Bayer PB. Mutable Characteristics and the Definition of Discrimination Under Title VII. UC Davis L Rev. 1986; 20:769.

[2] Weitz, R. (2003). The politics of women's bodies: Sexuality, appearance, and behavior. New York: Oxford University Press.

[3] Equal Rights Advocates. (2019). Gender Discrimination at Work. Www.Equalrights.Org.

[4] UN Women. (2015). Beijing Declaration and Platform for Action (ISBN: 978-1-936291-93-9). UN Women office. https://www.unwomen.org/en/digital-library/public ations/2015/01/beijing-declaration.

[5] Adams, L., Hilger, L., Moselen, E., Basi, T., Gooding, O., \& Hull, J. (2019, July). 2020 Sexual Harassment Survey. consultation on sexual harassment in the workplace, UK. https://assets.publishing.service.gov.uk/government /uploads/system/uploads/attachment_data/file/1002 873/2021-07-12_Sexual_Harassment_Report_FIN AL.pdf.

[6] United Nations Statistics Division. (2020, October 20). The World's Women 2020: Trends and Statistics.

https://worlds-women-2020-data-undesa.hub.arcgis $. \operatorname{com} /$.

[7] Olivetti, C. and Petrongolo, B. (2016), 'The evolution of gender gaps in industrialized countries', NBER Working Paper (WP No.21887).

[8] Equality and Human Rights Commission. (2018). Ending sexual harassment at work. https://www.equalityhumanrights.com/en.

[9] Qiao Hong, \& Liu Yuzhuo. (2021, September 3). Data report on the Gender Gap between Women and Men in the Workplace 2021. Cnwomen. http://www.cnwomen.com.cn/2021/03/09/9922219 5.html.

[10] Eurostat. (2019, July 3). Gender employment gap in the EU. Https://Ec.Europa.Eu/. https://ec.europa.eu/eurostat/web/products-eurostat -news/-/edn-20190307-1.

[11] Wang, X., Chui, W. H., \& Wang, Y. (2021). Perception of Gender Equality Matters: Targets' Responses to Workplace Sexual Harassment in Chinese Metropolises. Journal of interpersonal violence, 886260521997452. Advance online publication. https://doi.org/10.1177/0886260521997452.

[12] Premuzic, T. C. (2013, August 22). Why Do So 
Many Incompetent Men Become Leaders? Harvard Business Review. https://hbr.org/2013/08/why-do-so-many-incompet ent-men.

[13] Skullcandy Launch headphones that fit "female anatomy". (2017, May 25). Ingping.Com. https://zx.ingping.com/c_4/19343.html.

[14] Our World in Data. (2021). estimate, 1950 - 2020: annually interpolated demographic indicators total fertility (live birth per woman) [Dataset]. World Development Indicators - World Bank. http://data.worldbank.org/data-catalog/world-devel opment-indicators.

[15] Annually interpolated demographic indicators. (2019). [Dataset]. United Nations, Department of Economic and Social Affairs, Population Division. https://population.un.org/wpp2019/Download/Stan dard/Interpolated/.

[16] Rahman, A., Mehat, N., Hamzah, K., Sirajuddin, P., \& Malaysia, P. (2019). DISCRIMINATION AGAINST WOMEN IN WORKPLACE: A CASE STUDY ON HOTEL DRESS CODE. Journal of Hospitality and Networks, 1, 18-19. http://kuim.edu.my/journal/index.php/JHN. 